This is an electronic reprint of the original article. This reprint may differ from the original in pagination and typographic detail.

Author(s): Helttunen, Kaisa; Salorinne, Kirsi; Barboza, Tahnie; Barbosa, Hélène Campos; Suhonen, Aku; Nissinen, Maija

Title: $\quad$ Cation binding resorcinarene bis-crowns: the effect of lower rim alkyl chain length on crystal packing and solid lipid nanoparticles

Year: $\quad 2012$

Version:

Please cite the original version:

Helttunen, K., Salorinne, K., Barboza, T., Barbosa, H. C., Suhonen, A., \& Nissinen, M. (2012). Cation binding resorcinarene bis-crowns: the effect of lower rim alkyl chain length on crystal packing and solid lipid nanoparticles. New Journal of Chemistry, 36(3), 789-795. https://doi.org/10.1039/C2NJ20981K

All material supplied via JYX is protected by copyright and other intellectual property rights, and duplication or sale of all or part of any of the repository collections is not permitted, except that material may be duplicated by you for your research use or educational purposes in electronic or print form. You must obtain permission for any other use. Electronic or print copies may not be offered, whether for sale or otherwise to anyone who is not an authorised user. 


\title{
Cation binding resorcinarene bis-crowns: The effect of lower rim alkyl chain length to crystal packing and solid lipid nanoparticles
}

\author{
Kaisa Helttunen," Kirsi Salorinne, Tahnie Barboza, Hélène Campos Barbosa, Aku Suhonen and Maija \\ Nissinen*
}

\author{
Received (in $X X X, X X X)$ Xth $X X X X X X X X X 20 X X$, Accepted Xth $X X X X X X X X X 20 X X$ \\ DOI: $10.1039 / b 000000 x$
}

A group of seven resorcinarene bis-crown ethers (CNBC5) with two polyether bridges at the upper rim and either propyl, butyl, pentyl, heptyl, nonyl, decyl or undecyl groups at the lower rim were synthesized and their binding properties with $\mathrm{Cs}^{+}$were investigated by NMR titration. The bis-crowns form 1:2

10 complexes with $\mathrm{Cs}^{+}$with binding constants of $\log \mathrm{K} 4-5$. Crystal structures of bis-crowns and their $\mathrm{Cs}^{+}$ and $\mathrm{K}^{+}$complexes were studied and different packing motifs were found depending on the alkyl chain length. Short ethyl, propyl and butyl alkyl chains gave a layer or pillar packing where the polar and nonpolar regions cannot be distinguished, whereas, longer pentyl and decyl chains formed bilayers. Amphiphilic properties and self-assembly in water was studied by preparing solid lipid nanoparticles

15 (SLN) from the bis-crowns. All investigated compounds formed stable SLNs showing amphiphilic character, which in the case of the short chain bis-crowns probably rises from their locked boat conformation separating the polar face of the molecule from the non-polar face.

\section{Introduction}

Combining host-guest chemistry and surfactant properties into a 20 single molecule by structural design of supramolecules, nanoscale materials, i.e. films, particles or gels with host-guest functionality can be obtained. Calixarenes and resorcinarenes are macrocyclic supramolecular hosts well suited for this task since they have a concave binding cavity capable of binding various guest 25 molecules or ions. ${ }^{1-3}$ Resorcinarenes can be easily converted into amphiphilic molecules using long aliphatic aldehydes in their synthesis resulting in hydrophobic chains below the binding site. The upper rim of the resorcinarene bowl has innate hydrophilic character because of the $\mathrm{OH}$-functionalities derived from the 30 resorcinol, and in addition, the upper rim is readily available for further functionalization to improve the binding affinity and selectivity. The self-assembly of amphiphilic calixarenes and resorcinarenes in water and at interfaces into mono/bilayers, thin films, vesicles and micelles, and properties of these assemblies 35 have been studied avidly to extend the use of calixarenes. ${ }^{2,} 4$ Some recent examples of their potential applications include gene delivery, ${ }^{5,6}$ catalytic activity, ${ }^{7}$ liquid crystals ${ }^{8}$ and VOC sensing. ${ }^{9}$ In addition to host-guest properties, environmentally responsive functionalities, which change the organized structures from 40 micelles into larger vesicle according to $\mathrm{pH}$, have been

Nanoscience Center, Department of Chemistry, University of Jyväskylä, P.O. Box 35, Jyväskylä FI-40014, Finland. Tel: +358 50428 0804; Email:maija.nissinen@jyu.fi, kaisa.j.helttunen@jyu.fi

$45 \dagger$ Electronic Supplementary Information (ESI) available: Synthetic procedures, SEM images for SLN and details of crystal structue refinement. See DOI: 10.1039/b000000x/ prepared. ${ }^{10-12}$

50 Solid lipid nanoparticles (SLN), or particles prepared from solid lipids, are the latest addition to the family of drug carrier structures since the introduction of liposomes and polymeric nanoparticles, which are prepared from liquid lipids. ${ }^{13}$ The preparation process of SLNs leads to particles with diameters 55 from tens to few hundred or thousand nanometers, which can be loaded with drugs or other sensitive compounds and used for their protection and transport. Since calixarenes and resorcinarenes are usually solid materials at room temperature, they can be used for preparation of solid lipid nanoparticles and studies of their ${ }_{60}$ potential in encapsulation of biologically important guests, DNA for cell transfection and surface modification for drug targeting have been published. ${ }^{14-17}$

Calixarenes and resorcinarenes with crown ether bridges connecting the hydroxyl groups are very selective cation ${ }_{65}$ receptors called calixcrowns. ${ }^{18}$ Depending on the number of oxygen donors and thus the length and geometry of the crown bridge, calixcrowns have very good affinity towards alkali and alkaline earth metal cations and ammonium ions. ${ }^{19}$ Resorcinarene bis-crowns and their $\mathrm{K}^{+}, \mathrm{Cs}^{+}, \mathrm{Rb}^{+}$and $\mathrm{Ag}^{+}$complexes have 70 shown very interesting structural properties such as formation of layers, capsules and nanorods. ${ }^{20-22}$ Therefore, we have been interested in studying the effect of alkyl chain length in the crystal packing of the resorcinarene bis-crowns and their metal complexes, where it can (a) influence the twisting of the 75 resorcinarene framework and (b) induce a layer or bilayer packing when the hydrophobic effect of the alkyl chains becomes strong enough. The alkyl chain length also affects the amphiphilic properties and self-assembly in water, which was studied by 
preparing SLNs out of series of resorcinarene bis-crowns with short, medium and long alkyl chains.

\section{Results}

\section{Synthesis and complexation studies}

5 A group of seven resorcinarene bis-crown ethers or CNBC5, where $\mathrm{N}$ denotes to the number of carbons at the lower rim alkyl group and 5 to the number of oxygen donors in each polyether bridge, were prepared by O-alkylation of the free hydroxyl groups of various tetramethoxy resorcinarenes ${ }^{24}$ (Fig. 1). Propyl, 10 butyl, pentyl, heptyl, nonyl, decyl and undecyl groups at the resorcinarene lower rim were chosen for structural comparison with the previously synthesized $\mathrm{C} 2 \mathrm{BC} 5^{21,22}$ and to create amphiphilic bis-crowns. Synthesis was carried out in dry dimethyl formamide (DMF) using $\mathrm{Cs}_{2} \mathrm{CO}_{3}$ and ditosylated 15 tetra(ethylene glycol) yielding tetramethoxy resorcinarene biscrown ethers after purification as $15-30 \%$ yields.

Complexation of the bis-crowns with an alkali metal cation, cesium hexafluorophosphate, was carried out using NMR titration in order to investigate if the lower rim alkyl chain length has an 20 effect on the binding affinity. $\mathrm{C} 3 \mathrm{BC} 5, \mathrm{C} 5 \mathrm{BC} 5, \mathrm{C} 9 \mathrm{BC} 5$ and C11BC5 bind $\mathrm{Cs}^{+}$with the affinity of $\log \mathrm{K}_{11} 1.0-2.2$ and total binding constant of $\log \mathrm{K}_{11} \mathrm{~K}_{12}$ 4.0-5.0 (Table 1). C2BC5 has binding constant of $\log \mathrm{K}_{11} 1.75$ for $1: 1$ complex, ${ }^{21}$ which falls at the same magnitude of order as now determined $\log K_{11}$ values.

25 The second binding constant $\log \mathrm{K}_{12}$ is larger than the first binding constant for all investigated complexes. In case of C2BC5, $\mathrm{K}_{12}$ was not determined because Job plot showed that intrinsic water concentration over 1 molar equivalent relative to the host leads to 1:1 complexation. For C3BC5-C11BC5 such a 30 strong trend was not observed, water content being 1-2.5 molar equivalents except for the $13 \mathrm{~mol}$. eq. for C11BC5. In all cases a 1:2 binding model gave better fits than the 1:1 model.

\section{Crystal structures}

Resorcinarene bis-crowns

${ }_{35}$ Single crystals of resorcinarene bis-crowns were grown by slow evaporation from alcohol solutions. C4BC5 (structure C4) and C5BC5 (C5) crystallized in a triclinic P-1 without any solvent in their binding cavity or in the crystal lattice. Analysis of the conformational properties of individual molecules (Table 2)
40 revealed that the bis-crowns are in a boat or slightly twisted boat conformation and upright aryl rings (A and C) are tilted towards the cavity with $-8.3--10.7$ dihedral angles. Crown ether bridges are folded on top of the binding cavities closing the space inside.

Table 1. Binding constants for $\mathrm{Cs}^{+}$complexes in acetone-D6. ${ }^{a}$

\begin{tabular}{ccccc} 
& C3BC5 & C5BC5 & C9BC5 & C11BC5 \\
\hline $\log \mathrm{K}_{11}{ }^{b}$ & $1.04 \pm 0.18$ & $1.59 \pm 0.41$ & $1.49 \pm 0.60$ & $2.21 \pm 0.09$ \\
$\log \mathrm{K}_{11} \mathrm{~K}_{12}{ }^{c}$ & $4.43 \pm 0.03$ & $4.62 \pm 0.10$ & $4.06 \pm 0.19$ & $5.03 \pm 0.04$ \\
$\log \mathrm{K}_{12}{ }^{d}$ & 3.39 & 3.03 & 2.57 & 2.82
\end{tabular}

${ }_{45}{ }^{a} \mathrm{NMR}$ titration at $30{ }^{\circ} \mathrm{C}$, R-values $<7 \% .{ }^{b}$ Binding constant for reaction $\mathrm{H}+\mathrm{G} \leftrightarrow \mathrm{HG}^{c}{ }^{c}$ Total binding constant for $\mathrm{H}+2 \mathrm{G} \leftrightarrow \mathrm{HG}_{2} \cdot{ }^{d} \mathrm{~K}_{12}=$ $\mathrm{K}_{11} \mathrm{~K}_{12} / \mathrm{K}_{11}$.

The crystal packing of $\mathbf{C 5}$ can be described as "squeezed bilayer" where the upper rim interface of two opposing rows appears as if 50 compressed into one layer (Fig. 2). However, the polar and nonpolar layers can still be distinguished. Rows are aligned parallel to $\mathrm{A} / \mathrm{C}$ aryl plane direction (later $\mathrm{A} / \mathrm{C}$ direction, Fig. 1). The clockwise $(c w)$ counterclockwise $(c c w)$ enantiomers of the biscrowns are related by inversion symmetry. In $\mathbf{C 5}, c w$ and $c c w$ 55 enantiomers alternate in each bilayer in such a way that each $c w$ is facing up and is surrounded by a $c c w$ facing down on both sides. C4 has two molecules in the asymmetric unit, $I$ and $I I$, which could be assigned either to a boat or a slightly twisted boat conformation. Molecules pack in a pillar assembly with 60 alternating $I$ and $I I$ molecules (Fig. 3). Each pillar consists of either $c w$ enantiomers or $c c w$ enantiomers, which in turn form layers of $c w$ and $c c w$ enantiomers, but separation into polar and non-polar regions does not occur.

Long chain bis-crowns C9BC5, C10BC5 and C11BC5 65 crystallized readily from ethanol in a monoclinic lattice $(Z=8)$. Interestingly, most of these structures showed straight alignment of the alkyl groups in the bilayer assembly without disorder but had unresolvable disorder at the crown ether bridges and therefore these structures can only be considered as preliminary 70 structures.

\section{Alkali metal complexes}

Alkali metal complexes of the bis-crowns were studied by crystallizing CNBC5s with excess of potassium or cesium hexafluorophosphate in alcohols yielding 1:2 (host-guest) 75 complexes. When the binding pockets of the host are filled with

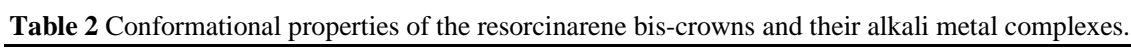

\begin{tabular}{|c|c|c|c|c|c|c|c|}
\hline & \multicolumn{2}{|c|}{$\mathrm{C4}^{\dagger}$} & \multirow[t]{2}{*}{ C5 } & \multirow[t]{2}{*}{$\mathrm{C} 2 \mathrm{~K} 2$} & \multirow[t]{2}{*}{ C3Cs2 } & \multirow[t]{2}{*}{ C5K2 } & \multirow[t]{2}{*}{ C10Cs2 } \\
\hline & $I$ & $I I$ & & & & & \\
\hline $\begin{array}{c}\text { Crystal packing } \\
\text { arrangement }\end{array}$ & pillar & pillar & squeezed bilayer & layer & $\begin{array}{c}\text { layer / shifted } \\
\text { capsule }\end{array}$ & $\begin{array}{c}\text { bilayer / shifted } \\
\text { capsule }\end{array}$ & $\begin{array}{c}\text { bilayer / shifted } \\
\text { capsule }\end{array}$ \\
\hline Conformation & boat & boat & twisted boat & boat & twisted boat & boat & boat \\
\hline Tilt $/^{\circ}$ & 3.7 & 5.7 & 8.9 & 1.4 & 7.0 & 3.3 & 1.1 \\
\hline Twist $/^{\circ}$ & 3.9 & 5.7 & 8.7 & 2.1 & 6.4 & 3.5 & 0.5 \\
\hline Distance $/ \AA^{a}$ & 4.79 / 8.01 & $4.87 / 8.00$ & $4.80 / 7.98$ & $5.28 / 7.98$ & $5.46 / 7.95$ & $5.26 / 7.98$ & $5.49 / 7.94$ \\
\hline $\begin{array}{c}\text { Dihedral angle } \\
\text { between opposite } \\
\text { rings/ }{ }^{o b}\end{array}$ & $-10.7 / 175.2$ & $-8.3 / 173.3$ & $-10.3 / 167.3$ & $14.4 / 151.4$ & $22.2 / 148.8$ & $11.8 / 147.0$ & $21.1 / 148.25$ \\
\hline $\begin{array}{c}\text { Dihedral angle } \\
\text { against methine } \\
\text { plane } /^{o c}\end{array}$ & $\begin{array}{l}80.0 / 89.1, \\
175.6 / 176.5\end{array}$ & $\begin{array}{c}88.9 / 82.9 \\
176.2 / 176.3\end{array}$ & $\begin{array}{l}86.4 / 83.2 \\
173.2 / 174.0\end{array}$ & $\begin{array}{c}96.5 / 97.9 \\
165.9 / 165.5\end{array}$ & $\begin{array}{c}100.3 / 101.5 \\
168.3 / 160.5\end{array}$ & $\begin{array}{l}96.4 / 95.3 \\
166.5 / 160.5\end{array}$ & $\begin{array}{c}100.6 / 100.5 \\
163.2 / 165.1\end{array}$ \\
\hline Cavity diameter/ $\AA^{d}$ & $5.17 / 5.11$ & $5.26 / 5.21$ & $4.59 / 4.79$ & $4.80 / 5.15$ & $5.42 / 5.28$ & $4.90 / 4.69$ & $5.08 / 5.23$ \\
\hline
\end{tabular}


cations the dihedral angles of $\mathrm{A} / \mathrm{C}$ aryl rings are $11.8-22.2^{\circ}$ and cavity diameters between $4.69-5.23 \AA$. The binding pocket of the bis-crowns is flexible and able to adjust its size slightly according to the size of the guest cation giving smaller cavity diameters for ${ }_{5} \mathrm{~K}^{+}$than $\mathrm{Cs}^{+}$complexes. Cations bind to the host with cation $-\pi$ $\left(\eta^{6}\right)$ interaction with a centroid-cation distance of 3.0-3.1 $\AA$ for $\mathrm{K}^{+}$and 3.2-3.3 for $\mathrm{Cs}^{+}$, and with $\mathrm{M}^{+}-\mathrm{O}$ interactions with methoxy group oxygens and 3-4 coordination bonds to the bridge $\left(\mathrm{O}-\mathrm{M}^{+} 2.70-3.54 \AA\right)$. One of the $\mathrm{PF}_{6}^{-}$anions is coordinated 10 between the two cations inside the binding pocket, which helps to reduce the charge repulsion between the cations. The other anion is located outside the cavity and creates short contacts between the complexes. Depending on the structure, alkyl chain length and the cation, the complexes pack in shifted capsule, layer or 15 bilayer assemblies.

C2BC5 has been previously crystallized as $\mathrm{KPF}_{6}$ complex in a capsule assembly. ${ }^{20}$ Now, another packing for $\mathrm{C} 2 \mathrm{BC} 5 \cdot 2 \mathrm{KPF}_{6}$ complex (C2K2) was obtained, forming layered packing without the capsule formation. When viewed on top, each $c w$ enantiomer 20 alternates with $c c w$ enantiomers within a layer, and therefore polar and non-polar sides cannot be distinguished. A side view (B/D direction) of the packing reveals that $c w$ and $c c w$ enantiomers are separated on their own stacks in a parallel alignment (Fig. 4).

${ }_{25} \mathrm{C}_{3} \mathrm{BC} 5 \cdot 2 \mathrm{CsPF}_{6}(\mathbf{C 3 C s} 2)$ crystallized with ethanol as a solvate in the crystal lattice. The conformation of the host is a twisted boat in contrast to the boat conformation of all the other complexes, which can be understood by analyzing the anion/solvent coordination of the cation. One of the $\mathrm{PF}_{6}{ }^{-}$anions is 30 coordinated between the two $\mathrm{Cs}^{+}$inside the cavity. In addition, a water molecule, not found in the other structures, is coordinated to $\mathrm{Cs} 2$ with $3.13 \AA \mathrm{Cs}-\mathrm{O}$ distance and has a short contact of 2.99 $\AA$ to the F10A of the (disordered) second $\mathrm{PF}_{6}^{-}$, which in turn is located close to the crown ether bridge of the opposite enantiomer 35 with F8A-C59 distance of $3.12 \AA$ (Fig 5). A pair of complexes, $c w$ and $c c w$ enantiomers, form a shifted capsule connected by the solvent-anion contacts. The top view of the complexes shows similar alternating pattern of $c w$ and $c c w$ enantiomers as in C2K2, and side view from the B/D direction shows a layered 40 packing, where shifted capsules form diagonal lines through the crystal. The role of the ethanol solvate is to fill the voids at the $\mathrm{B} / \mathrm{D}$ edges of the complexes, where they form H-bonded circles of four ethanol molecules without connecting to the host-guest complex.

$45 \mathrm{C} 5 \mathrm{BC} 5 \cdot 2 \mathrm{KPF}_{6}$ complex $(\mathbf{C 5 K 2})$ forms layers of single $c w$ or $c c w$ enantiomer which consist of rows aligned in the $\mathrm{A} / \mathrm{C}$ direction with $2.43 \AA$ shift between the molecules (15\% of complex width) and in the B/D direction with a $3.28 \AA$ (35\%) shift. In contrast to the $\mathbf{C 5}$, all alkyl chains are oriented straight 50 below the methine plane forming a clear bilayer packing. The upper rim interface of C5K2 forms shifted capsules with a $2.80 \AA$ dislocation of the B/D planes accounting for $30 \%$ of the width of a molecule (Fig. 6A). Similar packing was obtained for the C10BC5 $2 \mathrm{CsPF}_{6}$ complex (C10Cs2) despite the difference in 55 cation size and thus larger cavity diameter, but the longer alkyl groups expand the thickness of the bilayer up to $27.39 \AA$ (Fig. $6 \mathrm{~B})$.

\section{Solid lipid nanoparticles}

The ability of CNBC5's to form solid lipid nanoparticles was 60 tested to assess their self-assembling properties in water. Previously, calixarenes and resorcinarenes bearing long alkyl chains and hydrophilic functionalities at the upper rim have been used to prepare stable SLN's by solvent diffusion (solvent replacement) method. ${ }^{25,} 26$ The same method was applied for the ${ }_{65}$ CNBC5s, where approximately 5-7 mg of CNBC5 was dissolved in a small amount of THF and water was added to the solution by vigorous stirring, after which a cloudy suspension was formed. The size of the SLN's was analyzed using dynamic light scattering, which gave hydrodynamic diameters of 220-320 nm 70 for the particles with polydispersity indexes of $0.04-0.34$. The particle shape and size was confirmed by SEM images, which revealed spherical particles at a size distribution corresponding to the DLS measurements (Fig. 7). For calixarenes and resorcinarenes, it has been discovered that the size of the SLNs is 75 affected by several parameters: THF/water ratio, stirring speed, $\mathrm{pH}$ of the solution, and length of the alkyl chains of the calixarene. ${ }^{25,}{ }^{26}$ However, changes on the particle size are mostly affected by the final concentration of the calixarene in the suspension. Therefore in this study, other parameters except the 80 length of the alkyl chains and final concentration of the resorcinarene suspensions were kept constant. In the first series (Fig. 8) the molar concentration of the bis-crowns was constant and the diameters of the particles increase when the amount of carbon atoms at the alkyl chains increase. In the second series ${ }_{85}$ SLNs were prepared keeping the $\mathrm{mg} / \mathrm{L}$ concentration constant to make sure that the increased particle diameter was not originating from the increased amount (in milligrams) of bis-crown in the suspensions. The second series (Fig. 8) has very similar particle sizes than the first one, which indicates that the change in the 90 amount of bis-crowns between the two series has negligible effect. The variation in the particle size, although quite modest, is most likely caused by the different alkyl chain length of the biscrowns, which affects their amphiphilic properties.

\section{Discussion}

${ }_{95}$ Resorcinarene bis-crowns were shown to bind $\mathrm{Cs}^{+}$as $1: 1$ and 1:2 complexes in solution, 1:2 being the dominant species. There is some variation especially between the $\log \mathrm{K}_{11}$ values, giving 1.04 for C3BC5 and 3.31 for C11BC5. However, the higher $\log \mathrm{K}_{12}$ value for $\mathrm{C} 3 \mathrm{BC} 5$ partly compensates this difference when the 100 total binding constants are examined. In contrast to the previously examined $\mathrm{C} 2 \mathrm{BC} 5$, all compounds gave 1:2 complexes when more than 1 molar equivalent of water relative to the host was present in the solution. Therefore, what at first glance appears to be the effect of the alkyl chain length, may well be the indirect result of 105 desolvation of the cation. The sensitivity of the measurement towards water may explain some of the observed differences in the binding constants between the experiments.

Since the affinity of $\mathrm{C} 2 \mathrm{BC} 5$ towards $\mathrm{K}^{+}$is very low, $\log \mathrm{K}$ of 0.23 for the $1: 1$ complex, ${ }^{21}$ the binding constant was not 110 determined for the other bis-crown potassium complexes. However, the structural properties of solid state $\mathrm{K}^{+}$complexes were compared to the $\mathrm{Cs}^{+}$complexes with the purpose of exploring alternative crystal packing forms due to different cation size. Based on the results it seems that the size of the cation does 115 not have a direct influence on the packing, since similar 
structures were obtained for the different cations $(\mathbf{C} 2 \mathbf{K} 2$ and $\mathrm{C} 2 \mathrm{BC} 5 \cdot \mathrm{CsPF}_{6}$ complex ${ }^{21} \mathbf{C 5 K} 2$ and $\mathbf{C 1 0 C s 2}$ ). Instead, solvent coordination together with the cation size has more important role in the packing, which is seen by comparing the $\mathbf{C 2 K 2}$ and $\mathbf{C 3 C s 2}$ 5 and a capsule structure of $\mathrm{C} 2 \mathrm{BC} 5 \cdot 2 \mathrm{KPF}_{6}{ }^{20}$ with a water molecule coordinated inside the cavity. C3Cs2 also contains water, which is involved in the shifted capsule coordination. The larger diameter of $\mathrm{Cs}^{+}$probably prevents similar coordination of water and the tilted angle of $\mathrm{PF}_{6}{ }^{-}$between the cations inside the binding 10 pocket as in $\mathrm{C} 2 \mathrm{BC} 5 \cdot 2 \mathrm{KPF}_{6}$ capsules, and now coordination happens outside the binding pocket.

Twisting of the resorcinarene skeleton was observed in C4, C5 and $\mathbf{C 3 C s 2}$, and is therefore not limited to short alkyl chain biscrowns. Rather, all interaction in the lattice determine the 15 conformation of the resorcinarene to provide optimal close packing.

The effect of the lower rim alkyl chain length is connected to the amphiphilic nature of the bis-crowns. When alkyl chains are 2-4 carbons long, they have not been found to form bilayer ${ }_{20}$ packing with separated polar and non-polar parts. Instead, layers with alternating upper and lower rims in neighboring molecules or complexes are seen, and in addition, $\mathbf{C 4}$ formed a pillar type assembly with tilted methine carbon planes. For C5BC5 a squeezed bilayer in $\mathbf{C 5}$ and a bilayer in $\mathbf{C 5 K 2}$ were found, which 25 shows that five carbons is a limiting alkyl chain length for the bilayer type packing. For the long chain bis-crowns increased molecule size made crystallization more difficult and the structures also tend to show more disorder in either at the lower rim alkyl chains or at the crown ether bridges or both. Since

${ }_{30}$ C9BC5-C11BC5 had a very bad unresolvable disorder at the upper rim polyether bridges but quite well organized alkyl groups at the lower rim, this can be interpreted as an indication of stronger hydrophobic interactions at the lower rim, which drives the alkyl chains in the ordered packing whereas, the crown ether 35 bridges have more conformational freedom. As a result, complexation of cations in the binding pocket was attempted in order to rigidify the crown ether bridges and, thus, enable the crystal structure analysis of these molecules. This strategy has so far provided the structure of $\mathrm{Cs}^{+}$complex of $\mathrm{C} 10 \mathrm{BC} 5$ which has 40 very similar packing compared to C5K2

The second goal of this study was to investigate the selfassembly of CNBC5s in water by preparing SLNs. Bis-crowns are neutral amphiphilic molecules without $\mathrm{H}$-bond donors at their polar part. It is noteworthy, that also bis-crowns with $C_{2}, C_{3}$ and ${ }_{45} C_{4}$ alkyl chains, which do not arrange in a bilayered packing, indicating their amphiphilic character in the solid state, form these particles. In addition, SLNs with shorter than $C_{4}$ alkyl or acyl chains have not been previously reported for calixarenes or resorcinarenes to the best of our knowledge. The ability of these 50 molecules to form SLNs probably arises from the macrocyclic effect and the locked boat conformation, which separates the hydrophilic side of the compound from the hydrophobic side.

The diameter of the SLNs increased for the longer alkyl chains, which is in fact opposite result to those Coleman et al. ${ }^{27}$ 55 have obtained for the para-acyl-calix[9]arene SLNs. para-Acylcalix[4]arenes on the other hand have not shown clear trend in the SLN size for different alkyl chain lengths. ${ }^{25}$ Calix[9] arenes have larger, nine membered macrocyclic rings with enhanced conformational flexibility compared to resorcinarenes and 60 calix[4]arenes, which can lead to different arrangement of the amphiphiles during their self-assembly.

The prepared SLNs were stable enough to survive the vacuum treatment needed for the SEM sample preparation (gold coating) and in most cases the SLN suspensions were stable over several 65 months. Some exceptions to this rule were observed, a couple of times the samples formed a visible precipitation within a week or two accompanied with particle size increase. In the SEM images some of the samples showed signs of early aggregation tendency, and in a couple of samples complete assimilation of the smaller < $701 \mu \mathrm{m}$ particles into the substrate was seen. Also, the nature of the substrate has an effect during the sample preparation since on the hydrophobic carbon tape most of the particles deformed in contrast to the hydrophilic $\mathrm{SiO}_{\mathrm{x}}$ surface, where hydrophilic interactions with the surface could help to maintain the integrity 75 of the particles. According to the preliminary results C11BC5 seemed to give the most stable SLN's. However, further studies are needed to establish a more systematic survey on the properties of the resorcinarene bis-crown SLNs.

As a conclusion, resorcinarene bis-crowns bind $\mathrm{Cs}^{+}$in solution 80 and form solid state complexes with $\mathrm{Cs}^{+}$and $\mathrm{K}^{+}$. The lower rim alkyl chains affect the crystal packing and the amphiphilic properties since C2BC5-C4BC5 form layered packing, whereas, a bilayered packing typical for amphiphilic molecules is observed with $C_{5}$ and longer alkyl chains. The locked boat conformation of ${ }_{85}$ CNBC5 makes also the short chain derivatives behave as amphiphilic molecules, which form stable solid lipid nanoparticles with slight dependence between the SLN size and the alkyl chain length.

\section{Experimental}

\section{${ }_{90}$ X-ray crystallography}

Single crystal X-ray data were recorded on a Nonius Kappa CCD diffractometer with Apex II detector using graphite monochromatized $\mathrm{CuK}_{\alpha}(\lambda=1.54178 \AA)$ radiation at a temperature of $173 \mathrm{~K}$. The data were processed and absorption 95 correction was made to all structures with Denzo-SMN v.0.97.638 ${ }^{28}$ unless otherwise mentioned. The structures were solved by direct methods (SHELXS-97) and refined (SHELXL97) against $\mathrm{F}^{2}$ by full-matrix least-squares techniques using SHELX-97 software package (Table 3). ${ }^{29}$ The hydrogen atoms 100 were calculated to their idealized positions with isotropic temperature factors (1.2 or 1.5 times the $\mathrm{C}$ temperature factor) and refined as riding atoms. Crystal structure analysis was done using Mercury CSD 2.4 software. $^{30}$ Crystallographic data (excluding structure factors) for the structures in this paper have 105 been deposited with the Cambridge Structural Data Center as supplementary publication nos. CCDC 854053-854058. Copies of the data can be obtained free of charge from The Cambridge Crystallographic Data Centre via www.ccdc.cam.ac.uk/data_request/cif.

\section{${ }_{110}$ NMR titration}

$4 \mathrm{mM}$ CNBC5 was titrated with $\mathrm{CsPF}_{6}$ solution in acetone-D6 and the ${ }^{1} \mathrm{H}$ NMR spectra were recorded after each addition at 30 ${ }^{\circ} \mathrm{C}$. The shift the in aromatic resorcinarene signal at $6.005 \mathrm{ppm}$ for the free host was followed and the binding constants were 
calculated using WinEQNMR2 software. ${ }^{31}$

\section{SLNs}

Solid lipid nanoparticles were prepared by a solvent replacement method. $^{32} 5 \mathrm{mg}$ (or $5.27 \mu \mathrm{mol}, 5.2-7.8 \mathrm{mg}$ ) of CNBC5 was 5 dissolved in $1.5 \mathrm{ml}$ of THF and $50 \mathrm{ml}$ of purified water (Millipore, resistivity $>18 \mathrm{M} \Omega$ ) was added at a constant flow during $10 \mathrm{~s}$ into the organic solution under vigorous stirring at $800 \mathrm{rpm}$ with a magnetic stirrer. A cloudy suspension formed immediately. The suspension was stirred for an additional minute 10 and THF was removed under reduced pressure by a rotary evaporator $\left(44{ }^{\circ} \mathrm{C}, 60-70 \mathrm{mbar}\right)$. The volume of the suspension was adjusted to $50 \mathrm{ml}$ giving the final nanoparticle concentration of $100 \mathrm{mg} / \mathrm{L}$ (or $0.1 \mathrm{mM}$ ). The hydrodynamic diameter of the nanoparticles was measured using dynamic light scattering 15 (Beckman Coulter N5 Submicron Particle Size Analyzer) at $90^{\circ}$ angle in water using plastic cuvettes ( 3 min equilibration, $3 \mathrm{~min}$ measurement). Three samples for each SLN were measured. The morphology and size of the SLN's were analyzed using scanning electron microscopy (Zeiss EVO 50). Sample preparation: a drop 20 of SLN suspension was pipetted on a piece of silicon wafer attached by carbon tape to the sample holder and dried at ambient conditions. Samples were coated with gold (JEOL Fine coat Ion Sputter JFC-1100) prior to imaging.

\section{Acknowledgement}

${ }_{25}$ Authors wish to thank Hannu Salo for SEM imaging, and Mr. Reijo Kauppinen and M.Sc. Esa Haapaniemi for the help with the NMR measurements. Graduate School of Organic Chemistry and Chemical Biology, and Academy of Finland (project 128341) are acknowledged for funding.

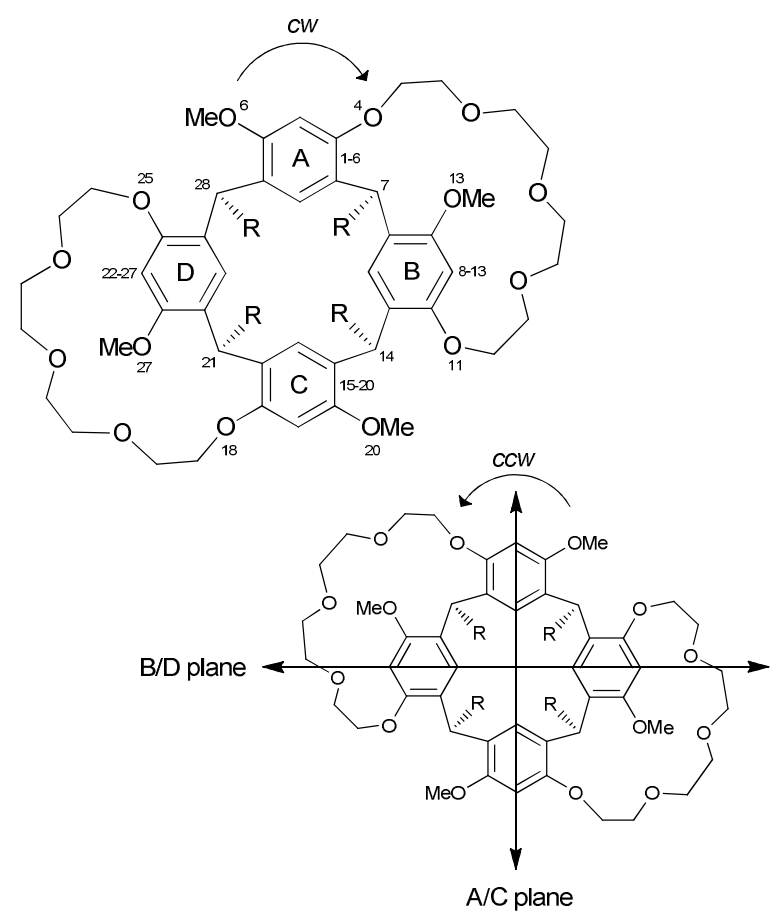

Fig. 1 Structure of the resorcinarene bis-crowns $\mathrm{CNBC} 5, \mathrm{R}=\mathrm{C}_{\mathrm{N}} \mathrm{H}_{2 \mathrm{~N}+1}$ where $\mathrm{N}=2,3,4,5,7,9,10,11$ with selected crystallographic numbering. $\mathrm{cw}$

and $c c w$ enantiomers are shown; A/C plane runs through the upright aryl rings $(\mathrm{A}$ and $\mathrm{C}$ ) and $\mathrm{B} / \mathrm{D}$ plane through parallel aryl rings $(\mathrm{B}$ and $\mathrm{D})$ respective to the methine plane $\mathrm{C} 7-\mathrm{C} 14-\mathrm{C} 21-\mathrm{C} 28$.
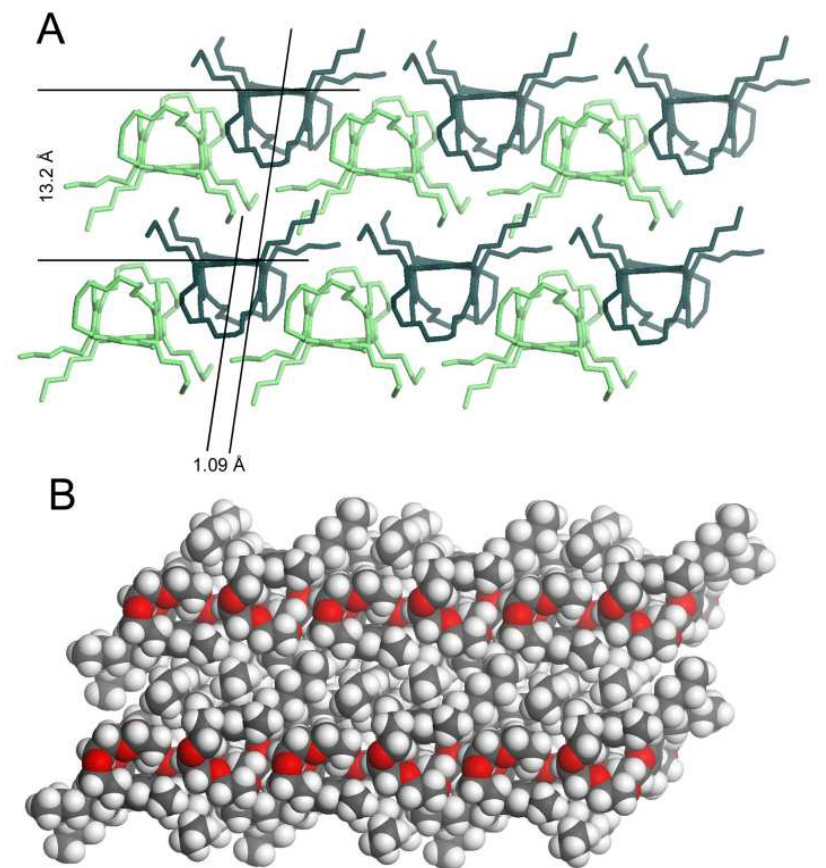

Fig. 2 Crystal packing of $\mathbf{C 5}$, flattened bilayer, in a stick model (A) with $c w$ enantiomers with light and $c c w$ in dark green, respectively, and a CPK representation (B), where the polar and non-polar regions are clearly visible. Disorder not shown for clarity.

A
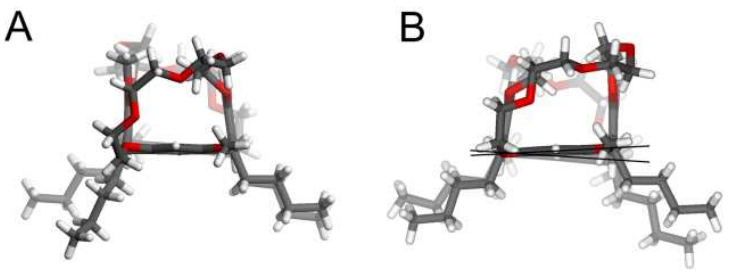

C
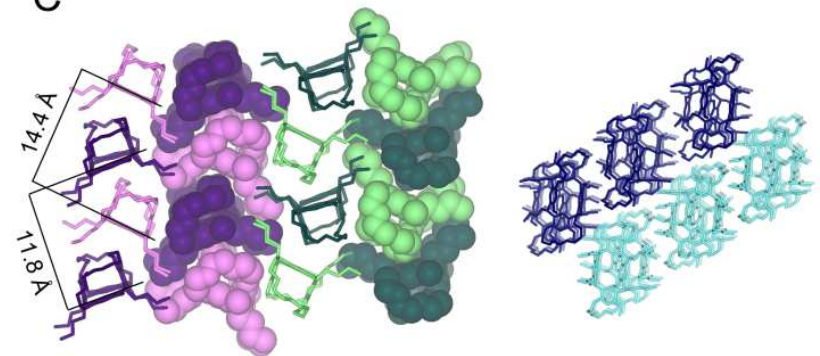

Fig. 3 Crystal structure of $\mathbf{C 4}$ (disorder not shown). $\mathbf{C 4}$ has two molecules, $I(\mathrm{~A})$ and $I I(\mathrm{~B})$ in the asymmetric unit, the twist angle in $I I$ indicated. C) Pillar packing of C4: $c w$ (up, purple) and $c c w$ (down, green) 45 enantiomers are separated in pillars with alternating $I$ (dark shade) and $I I$ (light shade). Each pillar consists of a single enantiomer with methine plane angle $\left(43.6^{\circ}\right)$ and distances indicated; a top view shows pillars of $c w$ and $c c w$ enantiomers in dark and light color, respectively. 


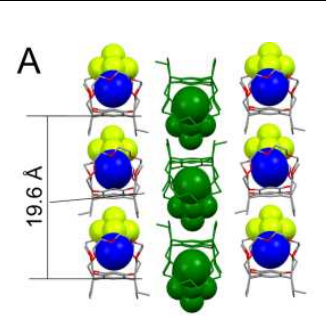

C

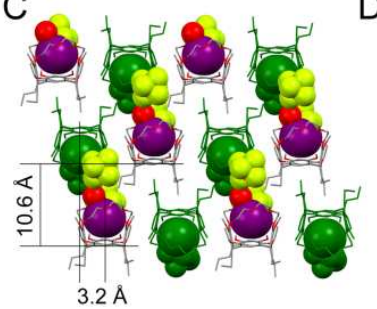

D

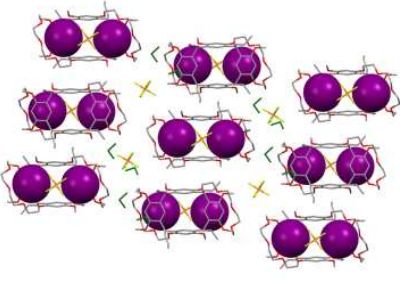

B

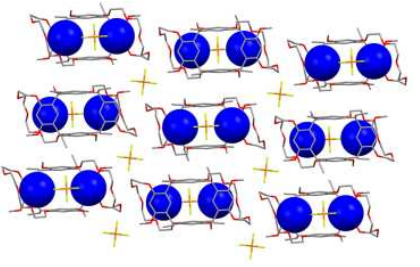

Fig. 4 Side and top views of the crystal packing of $\mathbf{C 2 K 2}$ layers (A, B) and C3Cs2 shifted capsules/ layers (C, D); side view: $c c w$ enantiomers facing down (green); top view of a layer: outlying anions and ethanol molecules (in D, green) shown as a stick model.
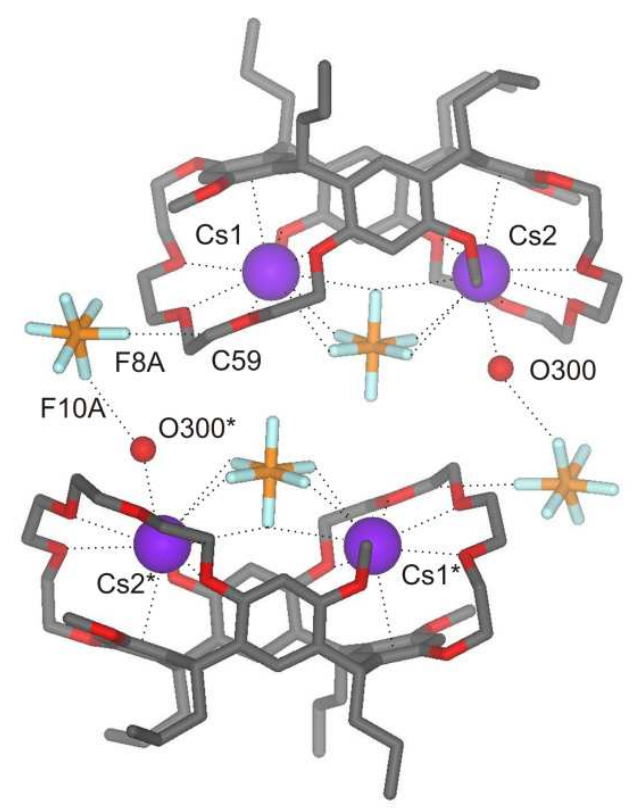

Fig. 5 C3Cs2 shifted capsule consisting of $c w$ and $c c w$ enantiomers, short contacts to the solvent and anions shown with dashed lines, atoms labelled with an asterisk are generated by a symmetry operation $-\mathrm{x}+1$, $\mathrm{y}+2,-\mathrm{z}+1$. Disorder not shown for clarity.

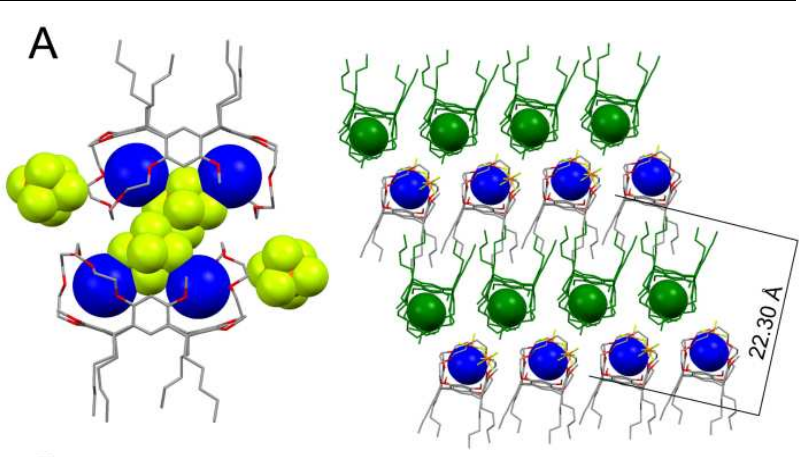

B

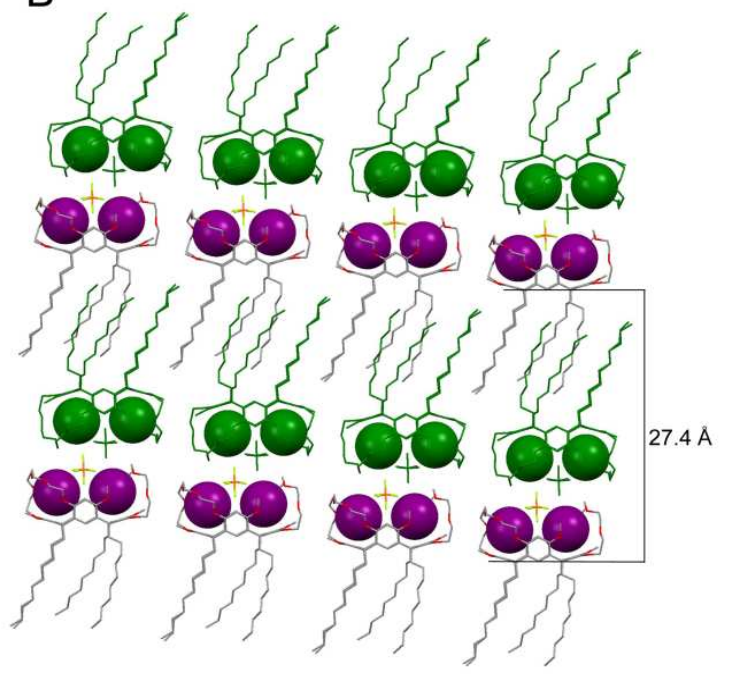

Fig. 6 C5K2: a front view of an offset capsule and a bilayer packing (A); 20 C10Cs2: a front view of a bilayer (B). ccw enantiomers in green color; outlying anions and disorder not shown.

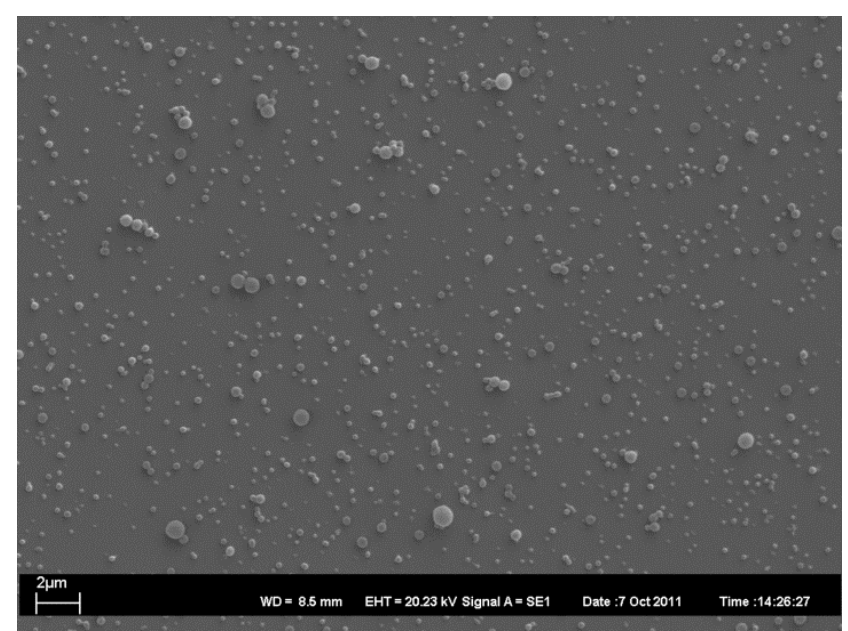

Fig. 7 SEM image of C11BC5 SLN on $\mathrm{SiO}_{x}$; spherical particles with mean diameter of $300 \mathrm{~nm}$ are shown. 


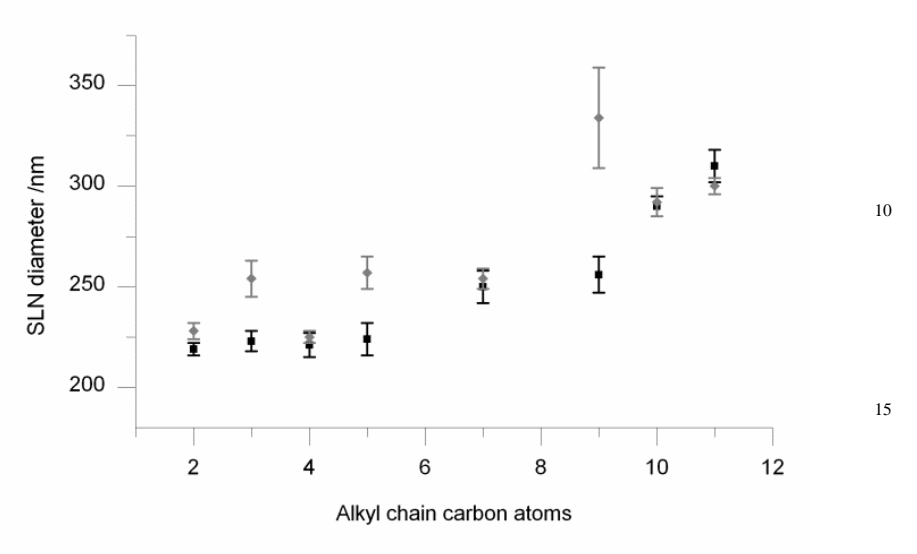

Fig. 8 SLN diameters for all CNBC5 (mean of the size distribution from DLS showing standard deviation). SLNs with a constant $0.1 \mathrm{mM}$ concentration (black) and with a constant mass $100 \mathrm{mg} / \mathrm{L}$ (grey) show $5 \quad$ increasing diameter for longer alkyl chains.

Table 3 Crystal structure parameters. ${ }^{a}$

\begin{tabular}{|c|c|c|c|c|c|c|}
\hline & $\mathrm{C} 4$ & $\mathbf{C 5}^{b}$ & C2K2 & C3Cs2 & C5K2 & C10Cs2 \\
\hline Composition & $\mathrm{C}_{64} \mathrm{H}_{92} \mathrm{O}_{14}$ & $\mathrm{C}_{68} \mathrm{H}_{100} \mathrm{O}_{14}$ & {$\left[\mathrm{~K}_{2}\left(\mathrm{PF}_{6}\right)\right.$} & {$\left[\mathrm{Cs}_{2}\left(\mathrm{PF}_{6}\right)\left(\mathrm{C}_{60} \mathrm{H}_{84} \mathrm{O}_{14}\right)\right.$} & {$\left[\mathrm{K}_{2}\left(\mathrm{PF}_{6}\right)\right.$} & {$\left[\mathrm{Cs}_{2}\left(\mathrm{PF}_{6}\right)\right.$} \\
\hline & & & $\left.\left(\mathrm{C}_{56} \mathrm{H}_{76} \mathrm{O}_{14}\right)\right] \mathrm{PF}_{6}$ & $\left.\left(\mathrm{H}_{2} \mathrm{O}\right)\right] \mathrm{PF}_{6} \cdot 2 \mathrm{C}_{2} \mathrm{H}_{6} \mathrm{O}$ & $\left.\left(\mathrm{C}_{68} \mathrm{H}_{100} \mathrm{O}_{14}\right)\right] \mathrm{PF}_{6}$ & $\left.\left(\mathrm{C}_{88} \mathrm{H}_{140} \mathrm{O}_{14}\right)\right] \mathrm{PF}_{6}$ \\
\hline FW & 1085.38 & 1141.48 & 1341.31 & 1695.18 & 1509.62 & 1977.76 \\
\hline Crystal system & Triclinic & Triclinic & Monoclinic & Triclinic & Triclinic & Triclinic \\
\hline Space group & P-1 & P-1 & $\mathrm{C} 2 / \mathrm{c}$ & P-1 & P-1 & P-1 \\
\hline$a / \AA$ & $15.5428(4)$ & $14.0441(5)$ & $36.7201(7)$ & $12.5169(3)$ & $10.1107(5)$ & $10.4675(4)$ \\
\hline$b / \AA$ & $16.2070(5)$ & $16.3664(6)$ & $19.6013(5)$ & $17.8145(5)$ & $17.014(1)$ & $16.8329(7)$ \\
\hline$c / \AA$ & $28.1062(9)$ & $16.5780(6)$ & $19.4874(6)$ & $18.0005(5)$ & $22.918(1)$ & $27.588(1)$ \\
\hline$\alpha /^{\circ}$ & $78.135(2)$ & $99.948(2)$ & 90 & $70.468(2)$ & $109.330(3)$ & $96.549(2)$ \\
\hline$\beta /^{\circ}$ & $88.922(2)$ & $104.812(2)$ & $116.801(1)$ & $79.987(2)$ & $95.789(3)$ & $97.404(2)$ \\
\hline$\gamma /{ }^{\circ}$ & $62.066(2)$ & $112.067(2)$ & 90 & $82.768(1)$ & $89.952(3)$ & $93.961(2)$ \\
\hline Volume $/ \AA^{3}$ & $6096.8(3)$ & $3256.7(2)$ & $12519.6(6)$ & $3715.3(2)$ & $3698.9(3)$ & $4771.6(3)$ \\
\hline $\mathrm{Z}$ & 4 & 2 & 8 & 2 & 2 & 2 \\
\hline$D_{\text {calcd }} / \mathrm{Mg} \cdot \mathrm{m}^{-3}$ & 1.182 & 1.164 & 1.423 & 1.515 & 1.355 & 1.377 \\
\hline $\mathrm{F}(000)$ & 2352 & 1240 & 5600 & 1732 & 1592 & 2056 \\
\hline$\mu / \mathrm{mm}^{-1}$ & 0.661 & 0.641 & 2.676 & 8.867 & 2.323 & 6.958 \\
\hline Crystal size/mm & $0.15 \times 0.10 \times 0.07$ & $0.26 \times 0.20 \times 0.10$ & $0.15 \times 0.10 \times 0.05$ & $0.30 \times 0.20 \times 0.10$ & $0.10 \times 0.10 \times 0.05$ & $0.20 \times 0.08 \times 0.06$ \\
\hline Meas. reflns & 29260 & 15745 & 17010 & 45717 & 16668 & 19576 \\
\hline Indep. reflns & 20072 & 10590 & 10802 & 12755 & 11625 & 13472 \\
\hline $\mathrm{R}_{\text {int }}$ & 0.0909 & 0.0593 & 0.0589 & 0.0587 & 0.1246 & 0.0927 \\
\hline $\mathrm{R}_{1}[I>2 \sigma(I)]$ & 0.0792 & 0.0852 & 0.0788 & 0.0449 & 0.0969 & 0.0826 \\
\hline $\mathrm{wR}_{2}[I>2 \sigma(I)]$ & 0.1761 & 0.2238 & 0.2001 & 0.1125 & 0.2355 & 0.1656 \\
\hline GooF on $F^{2}$ & 1.063 & 1.025 & 1.029 & 1.044 & 1.074 & 1.055 \\
\hline $\begin{array}{c}\text { Largest diff. } \\
\text { peak and hole/ e } \\
\AA^{-3}\end{array}$ & $0.470,-0.378$ & $0.580,-0.335$ & $0.713,-0.646$ & $0.882,-1.338$ & $0.828,-0.457$ & $1.027,-0.634$ \\
\hline
\end{tabular}




\section{Notes and references}

* C9: C2/c, $a=52.218(1), b=14.6337(3), c=21.2980(5), \beta=101.245(1)$, $\mathrm{V}=15962.2(6)$; C10: $\mathrm{C} 2 / \mathrm{c}, a=54.931(2), b=14.5212(5) c=21.3574(8)$, $\beta=102.354(2), \mathrm{V}=16641.4(1)$; C11: C2/c, $a=57.434(2), b=14.5337(4)$, $c=21.1864(7), \beta=100.590(1), \mathrm{V}=17383.6(1)$.

1 P. Timmerman, W. Verboom and D. N. Reinhoudt, Tetrahedron, 1996, 52, 2663-2704

2 L. Mandolini and R. Ungaro, Calixarenes in Action, Imperial College Press, Singapore, 2000, pp.271.

3 J. Vicens and V. Böhmer, in Topics in Inclusion Science, Vol. 3: Calixarenes: A Versatile Class of Macrocyclic Compounds, Kluwer Academic Publishers, Netherlands, 1991, pp.264.

4 K. Helttunen and P. Shahgaldian, New J. Chem., 2010, 34, 2704-2714.

5 R. V. Rodik, A. S. Klymchenko, N. Jain, S. I. Miroshnichenko, L. Richert, V. I. Kalchenko and Y. Mély, Chem. --Eur. J., 2011, 17, 5526-5538.

6 Y. Aoyama, Chem. --Eur. J., 2004, 10, 588-593.

7 L. Y. Zakharova, V. V. Syakaev, M. A. Voronin, F. V. Valeeva, A. R. Ibragimova, Y. R. Ablakova, E. K. Kazakova, S. K. Latypov and A. I. Konovalov, J. Phys. Chem. C, 2009, 113, 6182-6190.

8 L. Y. Zakharova, Y. R. Kudryashova, N. M. Selivanova, M. A. Voronin, A. R. Ibragimova, S. E. Solovieva, A. T. Gubaidullin, A. I. Litvinov, I. R. Nizameev, M. K. Kadirov, Y. G. Galyametdinov, I. S. Antipin and A. I. Konovalov, J. Membr. Sci., 2010, 364, 90-101.

9 A. F. Holloway, A. Nabok, A. A. Hashim and J. Penders, Sens. Transducers J., 2010, 113, 71-81.

10 M. Lee, S. Lee and L. Jiang, J. Am. Chem. Soc., 2004, 126, $12724-$ 12725.

11 N. Micali, V. Villari, G. M. L. Consoli, F. Cunsolo and C. Geraci, Phys. Rev. E, 2006, 73, 051904-1-051904-8.

12 S. Houmadi, D. Coquière, L. Legrand, M. C. Fauré, M. Goldmann, O. Reinaud and S. Rémita, Langmuir, 2007, 23, 4849-4855.

13 R. H. Müller, K. Mäder and S. Gohla, Eur. J. Pharm. Biopharm., 2000, 50, 161-177.

14 M. Pojarova, G. S. Ananchenko, K. A. Udachin, M. Daroszewska, F. Perret, A. W. Coleman and J. A. Ripmeester, Chem. Mater., 2006, 18, 5817-5819.

15 S. Ehrler, U. Pieles, A. Wirth-Heller and P. Shahgaldian, Chem. Commun. (Cambridge, U. K. ), 2007, 2605-2607.

16 P. Shahgaldian, M. A. Sciotti and U. Pieles, Langmuir, 2008, 24, 8522-8526.

17 L. Nault, A. Cumbo, R. F. Pretôt, M. A. Sciotti and P. Shahgaldian, Chem. Commun. (Cambridge), 2010, 46, 5581-5583.

18 C. Alfieri, E. Dradi, A. Pochini, R. Ungaro and G. D. Andreetti, J. Chem. Soc. , Chem. Commun., 1983, 1075-1077.

19 K. Salorinne and M. Nissinen, J. Inclusion Phenom. Macrocyclic Chem., 2008, 61, 11-27.

20 K. Salorinne and M. Nissinen, Org. Lett., 2006, 8, 5473-5476.

21 K. Salorinne and M. Nissinen, Tetrahedron, 2008, 64, 1798-1807.

22 K. Salorinne, O. Lopez-Acevedo, E. Nauha, H. Häkkinen and M. Nissinen, CrystEngComm, 2011, DOI: 10.1039/C1CE05737E.

23 K. Helttunen, N. Moridi, P. Shahgaldian and M. Nissinen, 2011, submitted.

24 M. J. McIldowie, M. Mocerino, B. W. Skelton and A. H. White, Org. Lett., 2000, 2, 3869-3871.

25 P. Shahgaldian, E. Da Silva, A. W. Coleman, B. Rather and M. J. Zaworotko, Int. J. Pharm., 2003, 253, 23-38.

26 J. Gualbert, P. Shahgaldian, A. Lazar and A. W. Coleman, J. Inclusion Phenom. Macrocyclic Chem., 2004, 48, 37-44.

27 S. Jebors, A. Leydier, Q. Wu, B. B. Ghera, M. Malbouyre and A. W. Coleman, J. Microencapsul., 2010, 27, 561-571.

28 Z. Otwinowski and W. Minor, Methods Enzymol., 1997, 276, 307-326.

29 G. M. Sheldrick, Acta Crystallogr. , Sect. A: Found. Crystallogr., 2008, A64, 112-122.
30 C. F. Macrae, I. J. Bruno, J. A. Chisholm, P. R. Edgington, P. McCabe, E. Pidcock, L. Rodriguez-Monge, R. Taylor, J. van de Streek and P. A. Wood, J. Appl. Crystallogr., 2008, 41, 466-470. 31 M. J. Hynes, J. Chem. Soc. , Dalton Trans., 1993, 311-312. 32 M. Skiba, D. Wouessidjewe, A. Coleman, H. Fessi,J.-P. Devissaguet, D. Duchene and F. Puisieux, Preparation and use of novel cyclodextrinbased dispersible colloidal systems in the form of nanospheres, US Patent 5718905, 1998. 